Article

\title{
The Effect of Production Parameters of Oxide Layers on Their Nanostructure, Nanomorphology, and Surface Free Energy
}

\author{
Władysław Skoneczny *(D), Mateusz Niedźwiedź ${ }^{\mathbb{D}}$ and Marek Bara $\mathbb{D}$ \\ Department of Surface Layers Technology, Faculty of Computer Science and Materials Science, \\ University of Silesia in Katowice, 40-007 Katowice, Poland; mateusz.niedzwiedz@us.edu.pl (M.N.); \\ marek.bara@us.edu.pl (M.B.) \\ * Correspondence: wladyslaw.skoneczny@us.edu.pl; Tel.: +48-32-2691-900
}

Received: 30 October 2018; Accepted: 12 November 2018; Published: 15 November 2018

check for updates

\begin{abstract}
Nanotechnology is currently a very promising field of materials science. One of the most recent directions of research in this field is the nanotechnology of the upper layers for applications in engineering kinematic systems. The paper presents the influence of the production parameters of $\mathrm{Al}_{2} \mathrm{O}_{3}$ oxide layers on an EN AW-5251 aluminum alloy substrate on the nanostructure, nanomorphology of these layers, and their energy condition. The energy level was determined on the basis of Surface-Free Energy (SFE), determined from wettability (contact) angle measurements using the Owens-Wendt method. Using systematic scanning, the geometric structure of the surface (SGS) was determined for the produced layers. By means of a scanning electron microscope (SEM), the surface morphology and structure, and the chemical composition of the layers (EDS) were analyzed. Computer analysis of the surface nanoporosity was performed by means of the ImageJ 1.50i program. It was noted in the investigations that the oxide layer production parameters induce changes in the surface free energy of the layers. Changes in the nanomorphology of the upper layers were also observed, depending on the anodizing parameters.
\end{abstract}

Keywords: nanolayers; SEM; EDS; nanomorphology; surface free energy

\section{Introduction}

Aluminum and its alloys belong to the group of materials most frequently used in production engineering, in particular in the aircraft, marine, and automotive industries. Aluminum and its alloys owe their wide application to their good strength properties in relation to low weight, good electrical conductivity, and relatively low price [1]. In order to increase the mechanical strength and corrosion protection of aluminum alloys, oxide layers are produced on their surface, usually by anodizing. The mechanical properties of oxide layers can be changed by altering their production parameters (temperature and current conditions, anodizing time, type of electrolyte) [2]. The mechanical properties of the upper layer are significantly influenced by its energy condition, which is defined by surface free energy (SFE). SFE is determined by measuring the wettability (contact angle), whose value decreases with an increasing SFE. The nanomorphology of the oxide layer surface also significantly influences the contact angle, and consequently, the SFE value. A change in the SFE value of the upper layer, in turn, has a significant effect on its abrasiveness and liquid adhesion $[3,4]$. Employing the droplet deposition method enables the wettability of oxide layer surfaces to be tested using liquids with different properties (polar and non-polar), and thus enables one to determine whether the layer is hydrophobic or hydrophilic [5]. Hydrophobic materials are in great demand today because of their wide use in industry. A major problem for the aviation industry is when water droplets deposit on 
power lines or on aircraft wings. Water freezes at low temperatures and the ice that settles often causes serious breakdowns or may even lead to catastrophic consequences [6-8]. The use of materials with hydrophobic layers can to a large extent solve this problem. At present, the most popular way to counteract ice accumulation is manual or mechanical (by vibration) deicing, which is quite troublesome and time-consuming $[9,10]$. Hydrophobic surfaces have a tendency to repel water molecules, and thus water does not freeze on their surface when the air temperature falls below $0{ }^{\circ} \mathrm{C}$. A surface is considered hydrophobic when its liquid contact angle is greater than $90^{\circ}$; less than this angle is considered a hydrophilic surface, i.e., those with high surface wettability. Surfaces with contact angles greater than $150^{\circ}$ are called superhydrophobic. They are surfaces with very low wettability, which very strongly repel water molecules [11,12]. Important applications of hydrophobic films also include coating clothing (to increase water impermeability and to reduce dirt), as well as vehicle bodywork and even windows, in which it prevents the adhesion of water molecules, thereby improving visibility without the need to use window wipers [13]. Hydrophobic coatings can be produced by several methods. However, most of them require a laboratory environment. The most common method used in practice is to produce oxide layers on aluminum alloys by anodizing and then modifying the layer with suitable substances. A lower SFE value of the oxide layer results in better hydrophobic properties, but in tribological applications, a higher value of surface free energy is more desirable because it better attracts lubricating fluids $[14,15]$. The following studies explain how the production parameters of oxide layers affect the surface morphology (nanoporosity) and the associated wettability of oxide layer surfaces.

\section{Materials and Methods}

\subsection{Research Material}

Oxide layers, $\mathrm{Al}_{2} \mathrm{O}_{3}$, were deposited on sheet metal plates made of the EN AW-5251 aluminum alloy with an area of $5 \times 10^{-4} \mathrm{~m}^{2}$ and thickness of $1 \times 10^{-3} \mathrm{~m}$. This alloy was chosen due to its good mechanical properties, low content of admixtures of other elements (Table 1) and high susceptibility of the alloy to anodizing.

Table 1. Chemical composition of EN-AW-5251 alloy.

\begin{tabular}{cccccccccc}
\hline \multicolumn{10}{c}{ Chemical Composition, Mass Concentration of the Element, [\%] } \\
\hline $\mathbf{S i}$ & $\mathbf{F e}$ & $\mathbf{C u}$ & $\mathbf{M n}$ & $\mathbf{M g}$ & $\mathbf{C r}$ & $\mathbf{Z n}$ & $\mathbf{T i}$ & other & $\mathbf{A 1}$ \\
\hline $\max 0.40$ & $\max 0.50$ & $\max 0.15$ & $0.1-0.5$ & $1.7-2.4$ & $\max 0.15$ & $\max 0.15$ & $\max 0.15$ & $\max 0.05$ & rest \\
\hline
\end{tabular}

Initial preparation of the samples included etching in a $10 \% \mathrm{KOH}$ solution and next, in a $10 \%$ $\mathrm{HNO}_{3}$. solution. An aqueous solution of $\mathrm{H}_{2} \mathrm{SO}_{4}, \mathrm{C}_{2} \mathrm{H}_{2} \mathrm{O}_{4}$, and $\mathrm{C}_{8} \mathrm{H}_{6} \mathrm{O}_{4}$ was used as the electrolyte. The addition of $\mathrm{C}_{8} \mathrm{H}_{6} \mathrm{O}_{4}$ acid ensures a hard oxide layer and allows the anodizing process to be carried out at room temperature. This in turn reduces the cost of intensive electrolyte cooling during anodizing. The anodizing conditions for the individual samples are presented in Table 2. Anodizing was carried out by means of the direct-current method, using a stabilized feeder, GPR-25H30D, for a constant electrical charge density of $180 \mathrm{~A} \cdot \mathrm{min} / \mathrm{dm}^{2}$. The electrolyte was stirred at a constant speed of $150 \mathrm{rpm}$ during the anodizing process. A lead plate was the cathode in the anodizing process.

After anodizing, the samples with the deposited layers were rinsed for $1 \mathrm{~h}$ in distilled water.

Table 2. Initial conditions of anodizing.

\begin{tabular}{cccc}
\hline Sample & Current Density I [A/dm $\left.{ }^{\mathbf{}}\right]$ & Electrolyte Temperature T [K] & Process Time $\mathbf{t}$ [min] \\
\hline A & 2 & 293 & 90 \\
B & 3 & 293 & 60 \\
C & 4 & 293 & 45 \\
D & 2 & 298 & 90 \\
E & 2 & 303 & 90 \\
F & 3 & 303 & 60 \\
\hline
\end{tabular}




\subsection{Research Methodology}

The thickness of the layers was measured with a Dualscope MP40 by Fischer, using the eddycurrent method. 10 measurements were performed along the length of the sample and then the average value was calculated.

A scanning microscope (SEM) was used to produce images of the nanomorphology of the $\mathrm{Al}_{2} \mathrm{O}_{3}$ layer surfaces and the nanostructure of those layers from metallographic specimens. A magnification of $50,000 \times$ was used for surface analysis, which allows observation of the nanopore distribution. The magnification applied to analyze the structure was $30,000 \times$.

Microscopic digital images were used for computer analysis of the oxide layer surfaces. The ImageJ 1.50i program was employed for the analysis. By applying appropriate procedures of computer image analysis, the stereological parameters of the surface were calculated. The nanoporosity surface share, the number of nanopores per unit area, and the average nanopore size were determined. Based on the data, histograms showing the distribution of nanopore surface area were made. The chemical composition of the oxide layers was also analyzed using an EDS analyzer.

To determine the surface roughness of the layers, surface geometric structure (SGS) tests were performed using a Form Talysurf Series 2, 3D profiler (Taylor Hobson). The tests were conducted using a systematic scanning method. The surface of the layers was measured over an area of $x=2.2 \mathrm{~mm}$; $y=2.2 \mathrm{~mm}$ with a sampling step $\Delta \mathrm{x}=0.001 \mathrm{~mm} ; \Delta \mathrm{y}=0.002 \mathrm{~mm}$. The preparation procedure consisted of levelling the sample and removing artifacts using two-sided thresholding- $\mathrm{Tp}=1 \%$. Next, the samples were rotated within the range of $0-2^{\circ}$ and trimmed to an area of $x=2 \mathrm{~mm} ; \mathrm{y}=2 \mathrm{~mm}$. The analysis included determination of the basic stereometric parameters from the amplitude group: $S a ; S q ; S p ; S v ; S t$; Ssk; Sku; Sz.

The contact angle of the surface was measured using four liquids. Two of the liquids were polar (water and glycerin) and two were non-polar (diiodomethane and $\alpha$-bromonaphthalene). The measurement consisted of applying 10 drops of liquid, each of $0.5 \mu \mathrm{L}$, onto the surface of the tested sample. Next, images of each drop were taken with a camera. The computer software enabled measurement of the contact angle for each drop, and the smallest and largest contact angles were rejected, while the remaining eight were used to calculate the average value. The contact angle values of the surface were used to determine the surface free energy (SFE) using the Owens-Wendt method. The Owens-Wendt method is applied for both polar and non-polar liquids. The contact angles of glycerin as a polar liquid and of $\alpha$-bromonaphthalene as a non-polar (dispersive) liquid were used for the calculations. In the Owens-Wendt method, it is assumed that the SFE value is the sum of two components: dispersive $\gamma_{\mathrm{s}}{ }^{\mathrm{d}}$ and polar $\gamma_{\mathrm{s}} \mathrm{p}$, and that there is an additive relationship between the two values:

$$
\gamma_{\mathrm{s}}=\gamma_{\mathrm{s}}^{\mathrm{d}}+\gamma_{\mathrm{s}}^{\mathrm{p}}
$$

where:

$\gamma_{\mathrm{s}}$-surface free energy of a solid;

$\gamma_{s}{ }^{d}$ - dispersive component of the surface free energy of the investigated material;

$\gamma_{\mathrm{s}}^{\mathrm{p}}$-polar component of the surface free energy of the investigated material.

\section{Results and Discussion}

The anodizing parameters, and more precisely the process time and the anodizing current value, were selected in such a way that the differences between the thickness of individual samples were as small as possible (constant value of the electrical charge density). The averaged values of the thickness measurements of the layers are presented in Table 3. The maximum differences between the thickness values of the oxide layers are in the range of $5 \mu \mathrm{m}$. 
Table 3. Juxtaposition of oxide layer thicknesses.

\begin{tabular}{ccccccc}
\hline Sample & A & B & C & D & E & F \\
\hline Thickness $[\mu \mathrm{m}]$ & 51.3 & 53.0 & 48.0 & 50.4 & 50.9 & 52.0 \\
Deviation $[\mu \mathrm{m}]$ & 0.9 & 1.3 & 1.2 & 0.6 & 0.8 & 1.9 \\
\hline
\end{tabular}

The structures of oxide layer surfaces consist of a thin barrier layer, adhering directly to the surface of the aluminum alloy and the surface layer. The barrier layer is formulated first on the surface of the aluminum alloy. It is not porous, the current conducts only in its thinner places, and its thickness is small and amounts to $0.5 \div 2 \%$ of the total layer thickness. The surface layer (Figure 1 ) shows a column-fibrous structure, oriented along the direction of layer growth due to the influence of the electric field in the electrochemical process. The aluminum oxide fibers are arranged parallel to each other forming free spaces between them, which are a migration channel of oxygen ions connecting with the material of the anode. Both the fiber diameters and dimensions of the space between the fibers depend on the parameters employed in the anodizing process (mainly electrolyte temperature and current density). Parallel alignment of the oxide fibers is obtained only when a substrate of high purity is used. Using aluminum alloys as the substrate of the oxide layer distorts the fibers, which are arranged in an irregular way and are directed at different angles. The results of research on the nanostructures of the $\mathrm{Al}_{2} \mathrm{O}_{3}$ layers obtained at different formation process temperatures are presented in Figure 1.

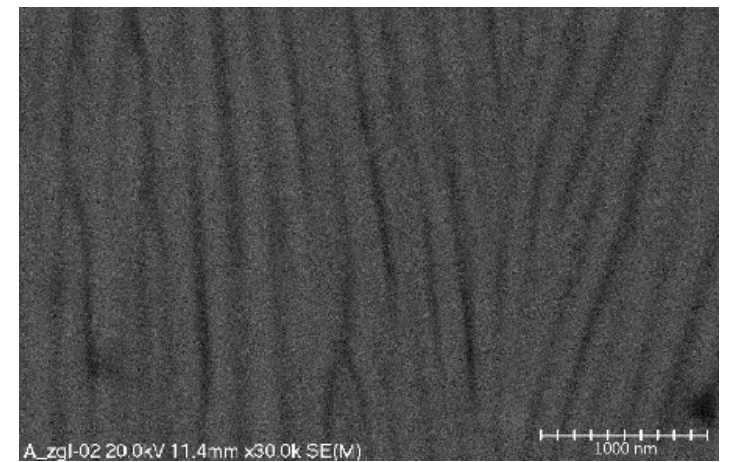

(a)

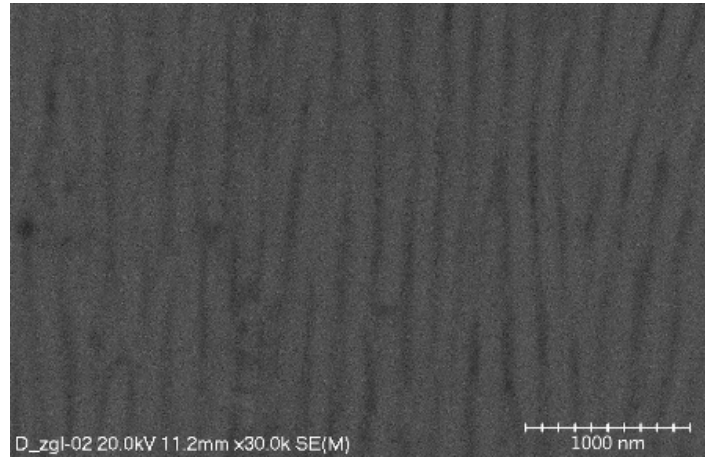

(b)

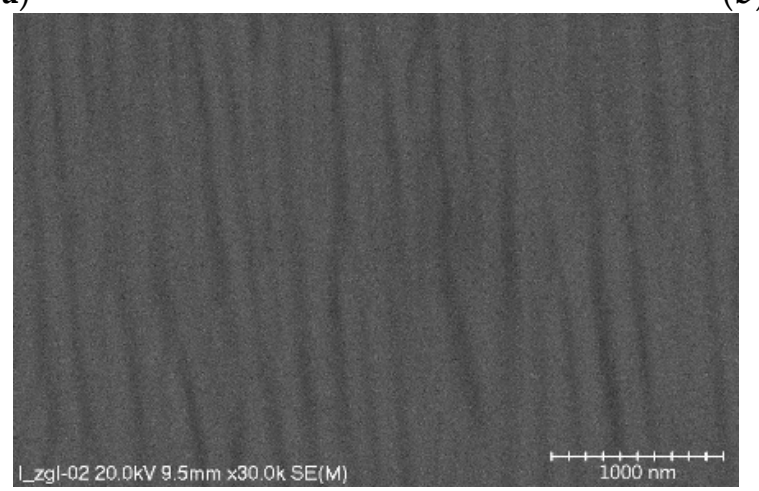

(c)

Figure 1. Cross-sectional image of columnar-fibrous structure of oxide layers produced at current density of $2 \mathrm{~A} / \mathrm{dm}^{2}$ in electrolyte at temperatures of: (a) 293; (b) 298; (c) $303 \mathrm{~K}$.

3D isometric visualizations of the layer surfaces are aimed at visualizing the measurement results for the surface geometric structure and the largest deviations from an even surface. Figure 2 presents the surface geometric structure for all tested layers. 


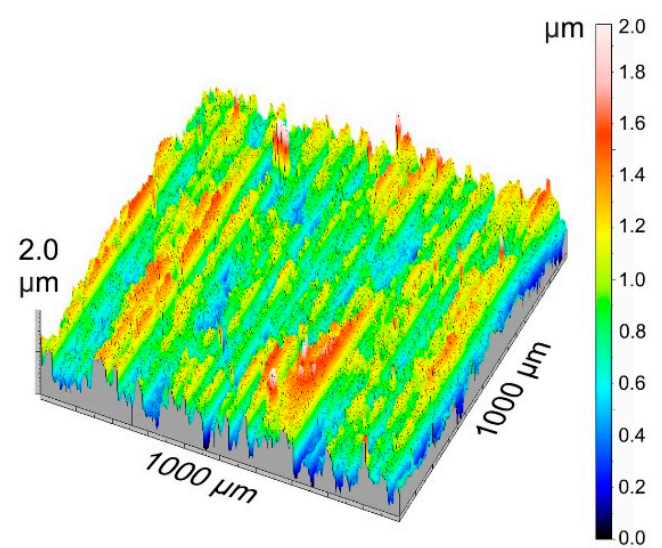

(a)

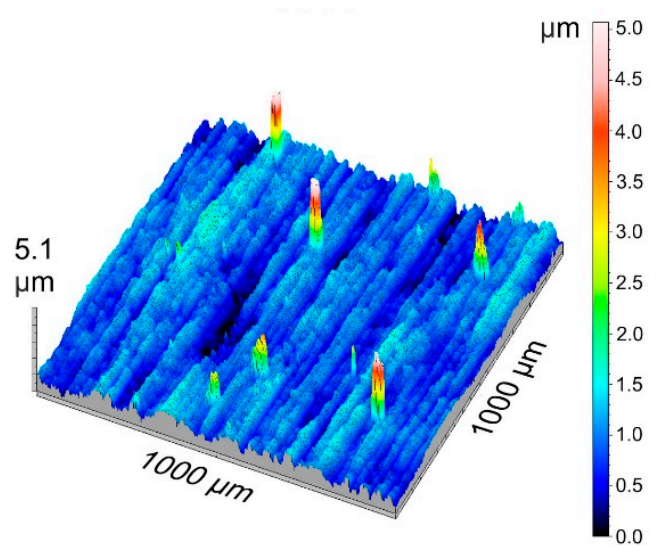

(c)

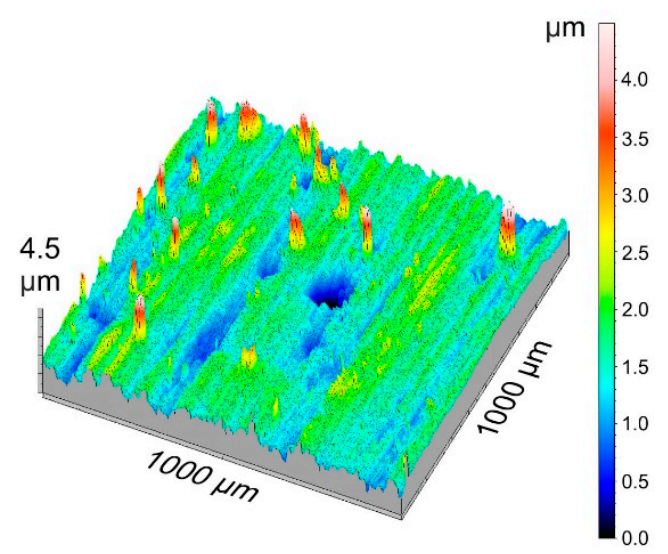

(e)

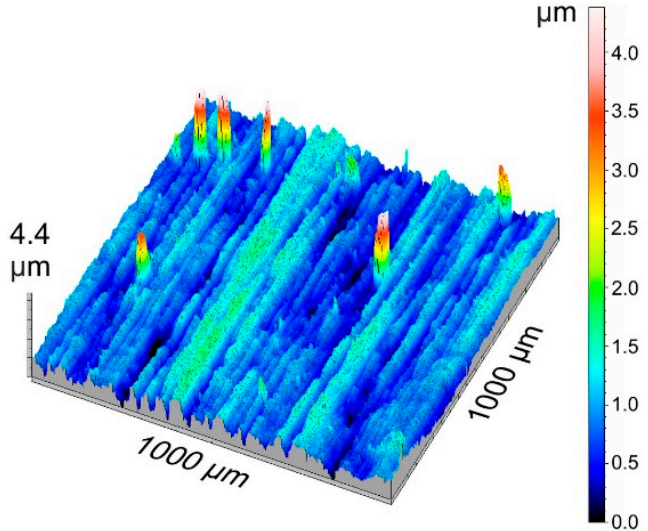

(b)

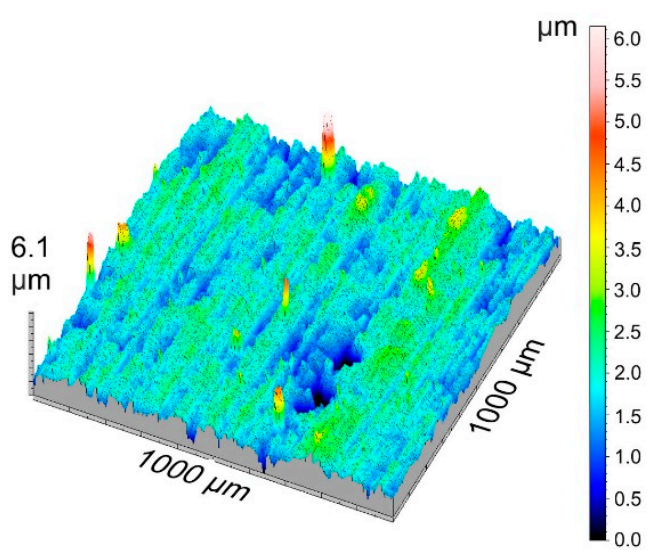

(d)

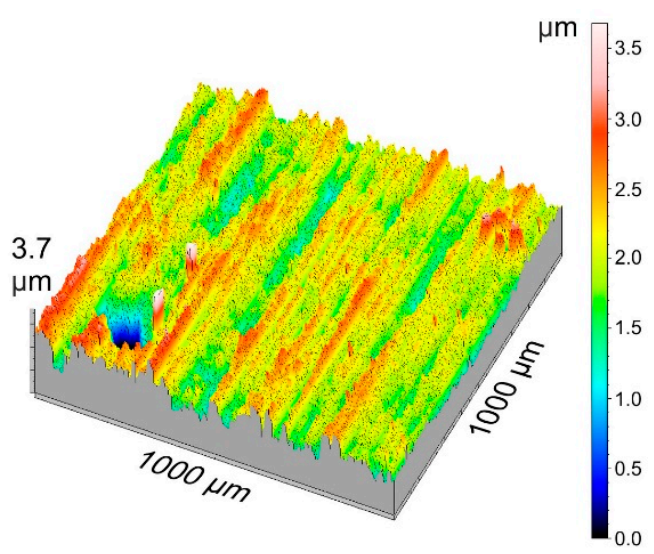

(f)

Figure 2. Top view of oxide layer surfaces (3D) (designations of samples in Table 1).

Table 4 shows the basic stereometric parameters of the amplitude group. The average arithmetic deviation of roughness, $S a$, and the average square deviation of roughness, $S q$, indicate a low surface roughness of the oxide coatings produced using the electrochemical method. These parameters change within a very small range. However, it can be noticed that as the temperature of the electrolyte in which the layers were produced grows, the value of parameters $S a$ and $S q$ increases. The maximum height of surface elevation, $S p$, had the lowest value $(1.28 \mu \mathrm{m})$ for Sample F, while the highest value of $S p(5.82 \mu \mathrm{m})$ was measured for Sample E. When analyzing the $S p$ parameter values, no correlation can be seen between the production conditions and the value of the maximum height of the surface elevations. Parameter Sv, which defines the maximum depth of the surface cavity, had the lowest 
value $(1.168 \mu \mathrm{m})$ for Sample E, while having the highest $(4.368 \mu \mathrm{m})$ for Sample G. It can be concluded that parameter $S v$ decreases as the current density increases for each of the temperatures. It is evident that the parameter values increase with an increase in the electrolyte temperature. The negative value of the Ssk parameter indicates a concentration of material near the apices of the profile or may be the result of scratches, to which this parameter is very sensitive. The lack of any correlation between the slope coefficient $S k u$ (which measures the sharpness of the profile ordinate density distribution curve) and the layer production parameters, indicates the presence of high and sharp apices or deep valleys on their surface profile.

Table 4. Amplitude parameters of surface geometric structure.

\begin{tabular}{|c|c|c|c|c|c|c|c|c|}
\hline Sample & $S a[\mu \mathrm{m}]$ & $S q[\mu \mathrm{m}]$ & $S p[\mu \mathrm{m}]$ & $S v[\mu \mathrm{m}]$ & $S t[\mu \mathrm{m}]$ & Ssk & $S k u$ & $S z[\mu \mathrm{m}]$ \\
\hline A & 0.277 & 0.348 & 1.952 & 1.488 & 3.44 & -0.209 & 3.402 & 2.918 \\
\hline B & 0.298 & 0.384 & 3.312 & 1.344 & 4.656 & 0.62 & 8.151 & 3.862 \\
\hline $\mathrm{C}$ & 0.294 & 0.378 & 3.696 & 1.168 & 4.864 & 0.674 & 8.639 & 4.186 \\
\hline $\mathrm{D}$ & 0.366 & 0.49 & 3.216 & 2.976 & 6.192 & -0.589 & 7.29 & 5.757 \\
\hline $\mathrm{E}$ & 0.323 & 0.477 & 5.824 & 4.368 & 10.192 & -0.733 & 20.315 & 8.214 \\
\hline $\mathrm{F}$ & 0.319 & 0.423 & 1.28 & 2.672 & 3.952 & -0.984 & 7.462 & 3.875 \\
\hline
\end{tabular}

Examinations of the chemical composition of the oxide layers were performed with an EDS spectrometer on cross-sections of the layers. Table 5 shows the chemical composition of an example of a layer with deviations. By weight, oxygen accounts for $31.89 \%$ of the chemical composition of the layer with $a+/-0.39 \%$ error, and aluminum accounts for $68.11 \%$ with $a+/-0.28 \%$ error. The above results are consistent with the composition resulting from the stoichiometric calculations of aluminum oxide. Figure 3 shows the EDS spectrum of the oxide layer.

Table 5. Chemical composition of oxide layer.

\begin{tabular}{ccccc}
\hline Element Line & Weight $\%$ & Deviation $\%$ & Atom $\%$ & Deviation $\%$ \\
\hline O K & 31.9 & $+/-0.4$ & 44.1 & $+/-0.5$ \\
Al K & 68.1 & $+/-0.3$ & 55.9 & $+/-0.2$ \\
\hline Total & 100.00 & & 100.00 & \\
\hline
\end{tabular}

Full scale counts: 19926

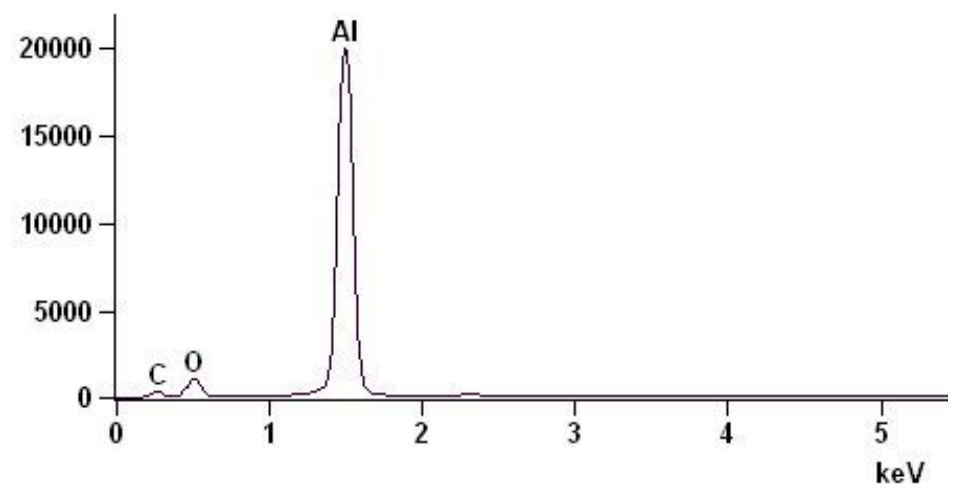

Figure 3. EDS spectrum of oxide layer.

Figure 4 show images of the nanomorphology of the oxide layer surfaces for all the electrolyte temperatures and current densities. The images show the surface porosity, characteristic of aluminum oxide layers, which is made up of nanopores of a cylindrical structure. When the formation of a layer begins, single rows of cells are formed in the initial phase. These form at the grain boundary, where the natural oxide layer has the lowest electrical resistance. During formation of the layer, a single cell 
is in linear contact with the six cylindrical cells surrounding it, thereby forming a hexagonal column. At the same time, the pore also changes into a star-shaped pore with six arms pointing towards the corners of the hexagon.

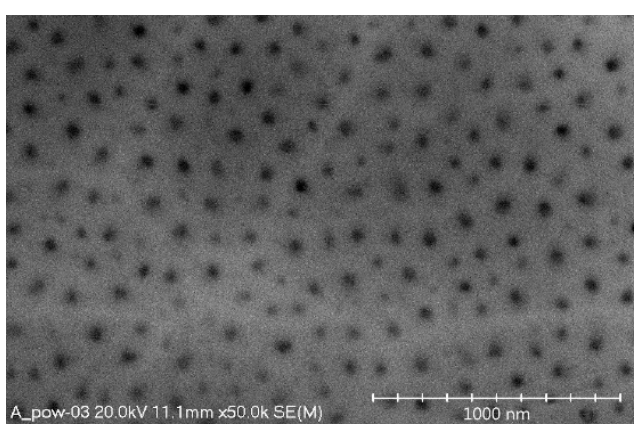

(a)

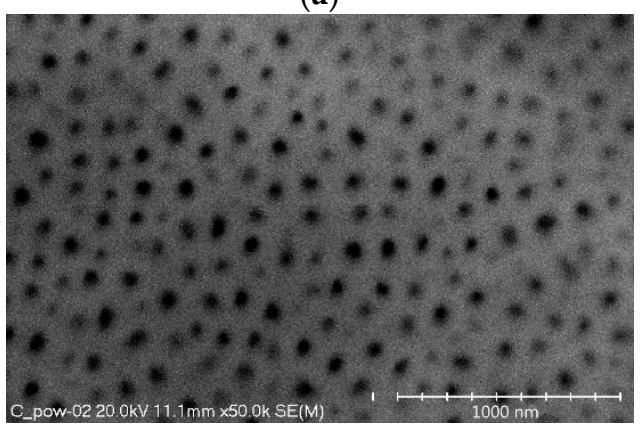

(c)

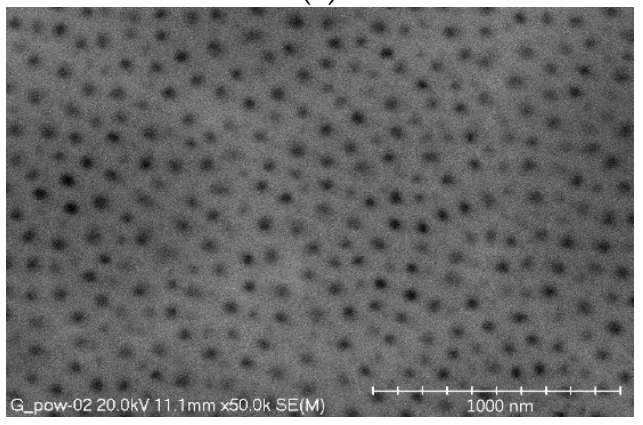

(e)

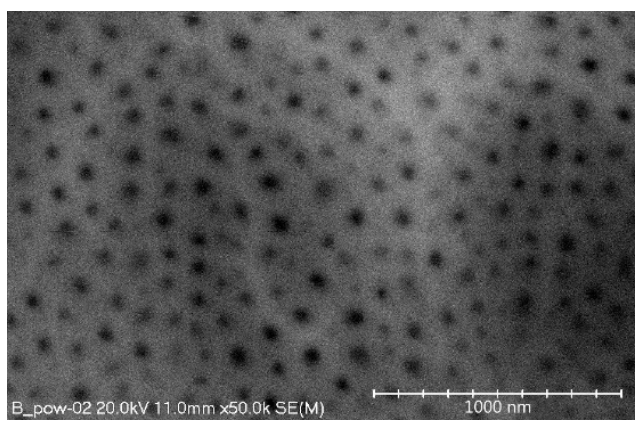

(b)

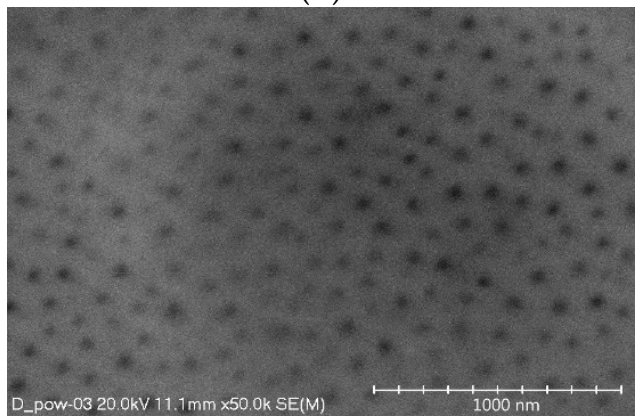

(d)

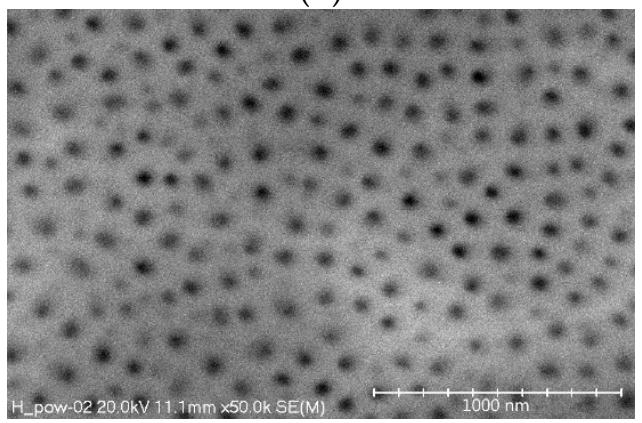

(f)

Figure 4. SEM image of nanopores in oxide layers (designations of samples in Table 1).

Computer analysis of the surfaces was performed on microscopic images of the oxide layers. All images of the oxide layer surfaces were processed using the same procedures. Based on the obtained data, histograms were prepared with the nanopore surface distribution in individual layers (Figure 5) and a table with the stereological parameters of the surface layers (Table 6).

Table 6. Stereological parameter values from computer analysis of surfaces.

\begin{tabular}{cccc}
\hline Sample & $\begin{array}{c}\text { Surface Share } \\
\text { Nanoporosity [\%] }\end{array}$ & $\begin{array}{c}\text { Number of } \\
\text { Nanopores/[ }\left[\mathbf{m m}^{2}\right]\end{array}$ & $\begin{array}{c}\text { Average Area } \\
\text { Nanopores }\left[\mathbf{n m}^{2}\right]\end{array}$ \\
\hline A & 5.5 & 31.4 & 1741 \\
B & 18.7 & 43.9 & 4294 \\
C & 15.4 & 38.0 & 4016 \\
D & 4.1 & 24.7 & 1637 \\
E & 6.5 & 51.7 & 1265 \\
F & 11.8 & 36.2 & 3265 \\
\hline
\end{tabular}




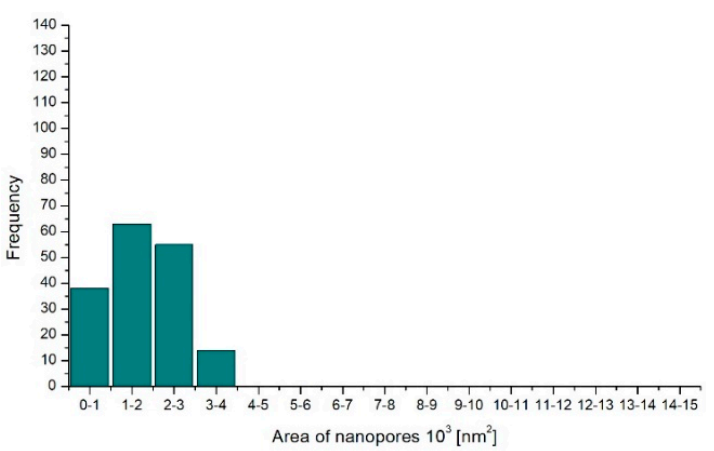

(a)

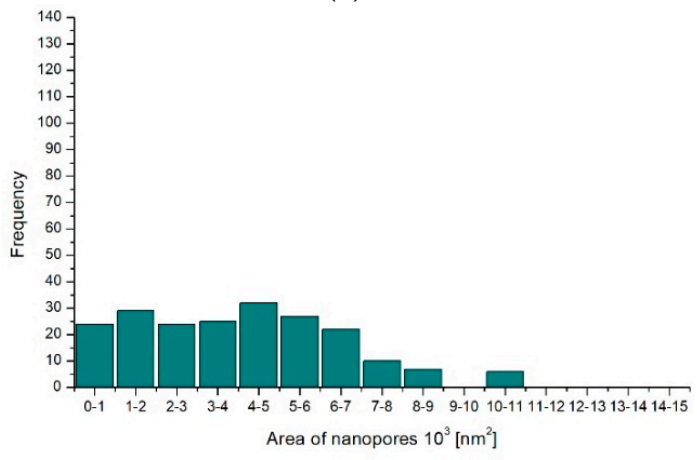

(c)

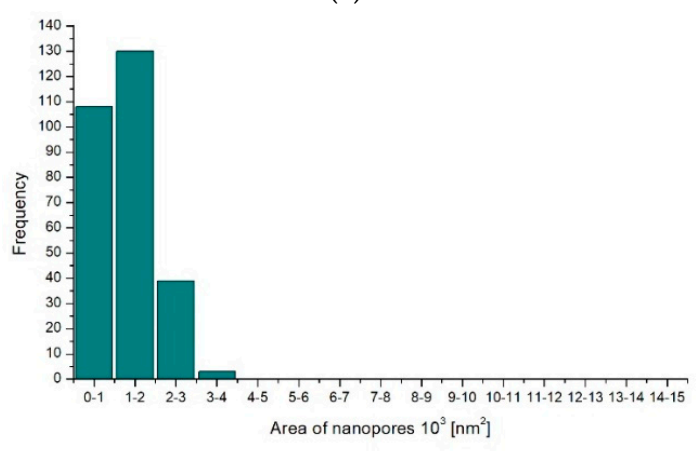

(e)

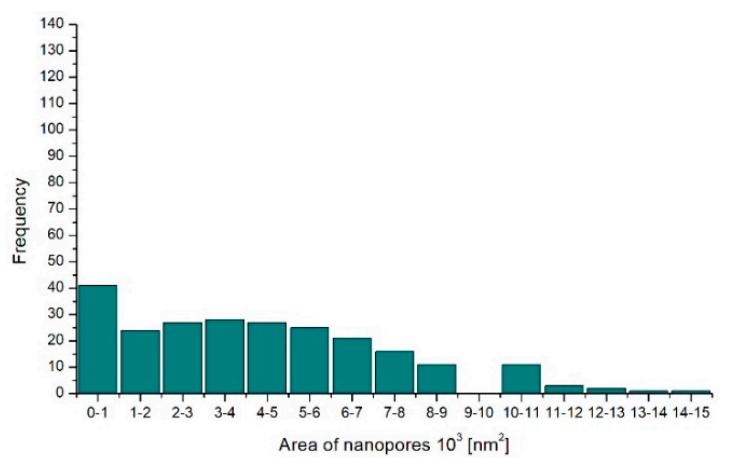

(b)

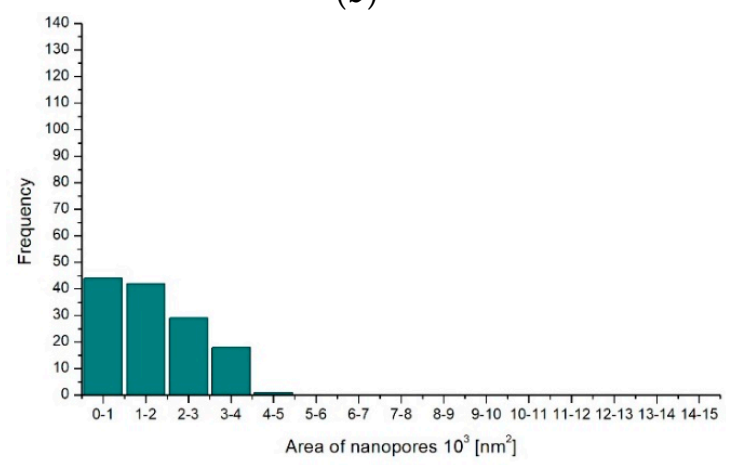

(d)

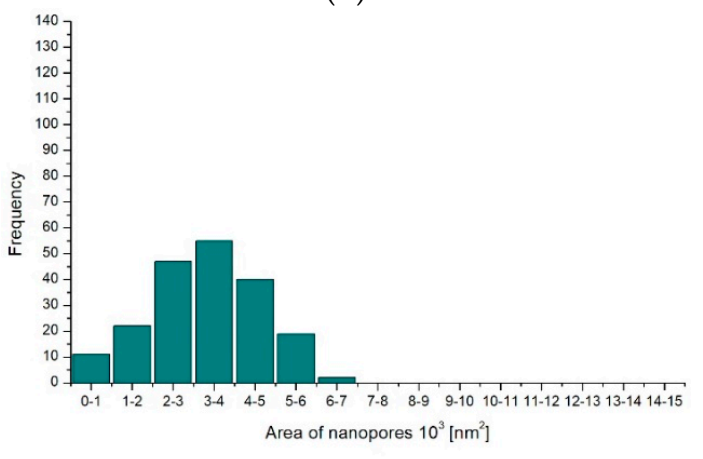

(f)

Figure 5. Histogram of prevalence of pores to their surface (designations of samples in Table 1).

The obtained investigation results indicate that both the current density of the process and the electrolyte temperature significantly affect the surface nanoporosity of the aluminum oxide. An increase in the current density from 2 to $3 \mathrm{~A} / \mathrm{dm}^{2}$ increases the surface-share value of nanopores and their number (Figure $5 \mathrm{a}-\mathrm{c}$, Table 6), while a further increase in the current density from 3 to $4 \mathrm{~A} / \mathrm{dm}^{2}$ reduces the value of the studied stereological parameters. The opposite occurs depending on the studied parameters and the temperature of the electrolyte. With an increase in the electrolyte temperature from 293 to $298 \mathrm{~K}$, the surface share of nanopores and their number decreases. However, a further increase in the electrolyte temperature causes an increase in the surface share of nanopores and their number (Figure 5a,d,e, Table 6).

Table 7 presents the contact angle measurements, tested with diiodomethane and distilled water, together with the standard deviations. The highest contact angle value for all the used liquids was obtained for distilled water, where for Sample B this angle was $84^{\circ}$. However, the surface of Sample B cannot be considered hydrophobic because the value of $90^{\circ}$ was not exceeded. The contact angles for diiodomethane were much smaller, with the largest being $49.66^{\circ}$ for Sample E. This was due in part to the density and viscosity of the liquid. 
Table 7. Contact angles of layers for diiodomethane and distilled water.

\begin{tabular}{ccccc}
\hline Sample & $\begin{array}{c}\text { Wettability Angles } \\
\left(\text { Diiodometan) }\left[{ }^{\circ}\right]\right.\end{array}$ & $\boldsymbol{\sigma}\left[^{\circ}\right]$ & $\begin{array}{c}\text { Wettability Angles } \\
\left(\text { Distilled Water) }\left[{ }^{\circ}\right]\right.\end{array}$ & $\left.\sigma{ }^{\circ}\right]$ \\
\hline A & 44.95 & 6.56 & 74.6 & 2.22 \\
B & 49.66 & 6.29 & 84.06 & 5.71 \\
C & 49.6 & 4.52 & 79.41 & 7.19 \\
D & 47.03 & 2.24 & 66.83 & 2.97 \\
E & 46.57 & 6.79 & 75.34 & 5.09 \\
F & 49.16 & 3.56 & 79.23 & 4.8 \\
\hline
\end{tabular}

Table 8 shows the contact angle measurements performed using $\alpha$-bromonaphthalene and glycerin, and the standard deviations.

Table 8. Contact angles for $\alpha$-bromonaphthalene and glycerin.

\begin{tabular}{ccccc}
\hline Sample & $\begin{array}{c}\text { Wettability Angles } \\
\left(\boldsymbol{\alpha} \text {-Bromonaphthalene) }\left[{ }^{\circ}\right]\right.\end{array}$ & $\boldsymbol{\sigma}\left[{ }^{\circ}\right]$ & $\left.\begin{array}{c}\text { Wettability Angles } \\
(\text { Glycerin })\end{array}{ }^{\circ}\right]$ & $\sigma\left[{ }^{\circ}\right]$ \\
\hline A & 22.7 & 3.28 & 70.1 & 6.64 \\
B & 27.51 & 3.46 & 79.55 & 3.17 \\
C & 27.91 & 3.32 & 74.54 & 5.42 \\
D & 23.84 & 3.03 & 70.77 & 3.36 \\
E & 24.08 & 1.47 & 67.92 & 2.55 \\
F & 27.09 & 1.83 & 76.68 & 4.08 \\
\hline
\end{tabular}

Table 8 shows the contact angles of the non-polar liquid ( $\alpha$-bromonaphthalene), for which the values are the lowest of all the applied liquids. The highest angle value was determined on Sample $F$ $\left(27.91^{\circ}\right)$, together with the polar liquid (glycerin), whose angles are significantly larger than those of the other two non-polar liquids but smaller than those of water. The largest contact angle when using glycerin was on Sample B $\left(79.55^{\circ}\right)$. The change in the contact angle when using $\alpha$-bromonaphthalene is influenced by the $S v$ parameter, i.e., the maximum depth of the surface cavity, which changes inversely in proportion to the contact angle. In summary, the contact angles of the oxide layer surface depend on the applied liquid and are the largest for distilled water. The oxide layer deposited on the aluminum substrate was a hydrophilic surface, since the maximum angle with water was $84.06^{\circ}$. It was found that the maximum depth of the surface cavity significantly affects the contact angle when using $\alpha$-bromonaphthalene. In other words, the smaller the maximum cavity, the larger the contact angle. The time between depositing the drop and the camera taking a picture also has an effect on the contact angle.

SFE was calculated by means of the Owens-Wendt method, which uses a non-polar liquid (in our case $\alpha$-bromonaphthalene) and a polar liquid (in our case glycerin). The results of the SFE calculation together with the deviations are presented in Table 9.

Table 9. Surface free energy values.

\begin{tabular}{cccc}
\hline Sample & SFE $\left[\mathrm{mJ} / \mathbf{m}^{2}\right]$ & Upper Deviation $\left[\mathrm{mJ} / \mathbf{m}^{2}\right]$ & Lower Deviation $\left[\mathrm{m} \mathbf{J} / \mathbf{m}^{2}\right]$ \\
\hline A & 46.81 & 1.73 & 1.59 \\
B & 42.51 & 2.44 & 1.84 \\
C & 43.77 & 2.58 & 3.53 \\
D & 49.88 & 1.93 & 1.82 \\
E & 46.2 & 2.33 & 1.67 \\
F & 44.05 & 1.69 & 1.65 \\
\hline
\end{tabular}

The research showed that the SFE value increases inversely proportionate to the contact angle. SFE increases in proportion to the maximum depth of the surface cavity, and the more porous the 
surface of the oxide layer, the higher the surface free energy. The value of surface free energy also varies with the current density of the oxide layer deposition. However, it cannot be clearly stated whether it increases inversely in proportion to the current density, due to the fact that some differences in the results are within the error limits.

\section{Conclusions}

On the basis of the conducted research, it can be affirmed that the presented technology enables programming of the properties of the layers to be obtained, including their nanostructure and nanomorphology. Analysis of the performed tests indicates a clear possibility of obtaining nanofibers of a specific diameter, which in turn causes a change in the nanomorphology and a change in the functional properties, e.g., of the surface free energy (Table 6).

The nanofibers of the oxide layer $\left(\mathrm{Al}_{2} \mathrm{O}_{3}\right)$ are always oriented perpendicular to the substrate. Every surface is characterized by micro-irregularities, resulting in deviations from a perfectly smooth surface Therefore, deviations from the columnar structure of the oxide nanolayer are possible. This results in the possibility of shaping a "Christmas tree" nanostructure (Figure 1a), which means that entire groups of oxide nanofibers are directed at different angles.

The research showed an opposite tendency of changes in the surface share of nanopores and their number to the surface free energy values, with varying oxide layer production parameters.

As the current density increased during anodizing, the value of the surface geometric structure, $S v$, decreased. It can be concluded that oxide layers in an unmodified form exhibit hydrophilic properties because the contact angle did not exceed $90^{\circ}$ for any of the samples. The dependence of both the contact angle and SFE on the $S v$ parameter was also observed. It was found that the contact angle value increased inversely in proportion to the maximum depth of the surface cavity, while the SFE value increased proportionally to this parameter.

Author Contributions: W.S. contributed to the conception of the study and modified the manuscript; M.N. performed the analyses and wrote the manuscript; M.B. conducted the tests.

Funding: This research received no external funding.

Conflicts of Interest: The authors declare no conflicts of interest.

\section{References}

1. Mokhtari, S.; Karimzadeh, F.; Abbasi, M.H.; Raeissi, K. Development of super-hydrophobic surface on $\mathrm{Al} 6061$ by anodizing and the evaluation of its corrosion behavior. Surf. Coat. Technol. 2017, 324, 99-105. [CrossRef]

2. Bara, M.; Kmita, T.; Korzekwa, J. Microstructure and properties of composite coatings obtained on aluminium alloys. Arch. Metall. Mater. 2016, 61, 1107-1112. [CrossRef]

3. Ghanbari, A.; Attar, M.M. Surface free energy characterization and adhesion performance of mild steel treated based on zirconium conversion coating: A comparative study. Surf. Coat. Technol. 2014, 246, 26-33. [CrossRef]

4. Sobolewski, S.; Lodes, M.A.; Rosiwal, S.M.; Singer, R.F. Surface energy of growth and seeding side of free standing nanocrystalline diamond foils. Surf. Coat. Technol. 2013, 232, 640-644. [CrossRef]

5. Rudawska, A.; Jacniacka, E. Analysis for determining surface free energy uncertainty by the Owen-Wendt method. Int. J. Adhes. Adhes. 2009, 29, 451-457. [CrossRef]

6. Shen, Y.; Tao, H.; Chen, S.; Zhu, L.; Wang, T.; Tao, J. Icephobic/anti-icing potential of superhydrophobic Ti6Al4V surfaces with hierarchical textures. RSC Adv. 2015, 5, 1666-1672. [CrossRef]

7. Kulinich, S.; Farzaneh, M. Ice adhesion on super-hydrophobic surfaces. Appl. Surf. Sci. 2009, 255, 8153-8157. [CrossRef]

8. Cao, L.; Jones, A.K.; Sikka, V.K.; Wu, J.; Gao, D. Anti-icing superhydrophobic coatings. Langmuir 2009, 25, 12444-12448. [CrossRef] [PubMed]

9. Zuo, Z.; Liao, R.; Guo, C.; Yuan, Y.; Zhao, X.; Zhuang, A.; Zhang, Y. Fabrication and antiicing property of coral-like superhydrophobic aluminum surface. Appl. Surf. Sci. 2015, 331, 132-139. [CrossRef] 
10. Charpentier, T.V.; Neville, A.; Millner, P.; Hewson, R.W.; Morina, A. Development of anti-icing materials by chemical tailoring of hydrophobic textured metallic surfaces. J. Colloid Interface Sci. 2013, 394, 539-544. [CrossRef] [PubMed]

11. Wexler, J.S.; Grosskopf, A.; Chow, M.; Fan, Y.; Jacobi, I.; Stone, H.A. Robust liquidinfused surfaces through patterned wettability. Soft Matter 2015, 11, 5023-5029. [CrossRef] [PubMed]

12. Ohtsu, N.; Hirano, Y. Growth of oxide layers on NiTi alloy surfaces through anodization innitric acid electrolyte. Surf. Coat. Technol. 2017, 325, 75-80. [CrossRef]

13. Liu, P.; Zhu, Y.; Zhang, S. Hydrophilicity characterization of $\mathrm{Al}_{2} \mathrm{O}_{3}$-coated MoS2 particles by using thin layer wicking and sessile drop method. Powder Technol. 2015, 281, 83-90. [CrossRef]

14. Ruan, M.; Li, W.; Wang, B.; Deng, B.; Ma, F.; Yu, Z. Preparation and anti-icing behavior of superhydrophobic surfaces on aluminum alloy substrates. Langmuir 2013, 29, 8482-8491. [CrossRef] [PubMed]

15. Thieme, M.; Worch, H. Ultrahydrophobic aluminium surfaces: Properties and EIS measurements of different oxidic and thin-film coated states. J. Solid State Electrochem. 2006, 10, 737-745. [CrossRef]

(C) 2018 by the authors. Licensee MDPI, Basel, Switzerland. This article is an open access article distributed under the terms and conditions of the Creative Commons Attribution (CC BY) license (http://creativecommons.org/licenses/by/4.0/). 